\title{
Investigation of the Morphological Structure of Thin Cobalt Films by AFM and TEM
}

\author{
W. Szmaja, J. Balcerski, W. KozŁowski \\ Department of Solid State Physics, University of Łódź \\ Pomorska 149/153, 90-236 Łódź, Poland
}

J. Grobelny and M. Cichomski

Department of Chemical Technology and Environmental Protection

University of Lódź, Pomorska 163, 90-236 Łódź, Poland

Thin obalt films, $40 \mathrm{~nm}$ and $100 \mathrm{~nm}$ in thickness, were evaporated at an incidence angle of $45^{\circ}$ in a vacuum of about $10^{-5}$ mbar, simultaneously on unheated glass substrates and $\mathrm{NaCl}$ crystals. The magnetic microstructure of these films was investigated in a previous paper. In the present paper, to obtain an insight into relation between the magnetic microstructure and the morphological structure, we studied the latter structure with atomic force microscopy and transmission electron microscopy. For the films $40 \mathrm{~nm}$ as well as $100 \mathrm{~nm}$ thick, the presence of contribution of the shape anisotropy (related to the geometric alignment of the grains of the film) to the magnetic anisotropy of the film was found. Nevertheless, for the films investigated, we could not detect crystallographic texture.

PACS numbers: 68.55.Jk, 68.37.Ps, 68.37.Lp

\section{Introduction}

In the previous paper [1] it was shown that the magnetic microstructure of cobalt films $40 \mathrm{~nm}$ and $100 \mathrm{~nm}$ thick, evaporated at an incidence angle of $45^{\circ}$ in a vacuum of about $10^{-5}$ mbar, consists of in-plane magnetized domains running predominantly in the direction perpendicular and parallel to the incidence plane, respectively.

In the present paper, we present results of an investigation of the morphological structure of these films. The study was carried out using atomic force microscopy (AFM) and transmission electron microscopy (TEM).

\section{Experimental}

The specimens studied were cobalt films $40 \mathrm{~nm}$ and $100 \mathrm{~nm}$ thick. They were evaporated at an incidence angle of $45^{\circ}$ in a vacuum of about $10^{-5}$ mbar. 
A heater composed of two $\mathrm{Al}_{2} \mathrm{O}_{3}$ tubes threaded with tungsten wire was used. The films were deposited simultaneously on unheated glass substrates and $\mathrm{NaCl}$ crystals. The morphological structure of the films was investigated by AFM and TEM.

\section{Results and discussion}

Figure 1 shows $1 \mu \mathrm{m} \times 1 \mu \mathrm{m}$ image of the surface of the cobalt film $40 \mathrm{~nm}$ in thickness, recorded by AFM. It is seen that the morphological structure is composed of grains elongated slightly in the direction perpendicular rather than parallel to the incidence plane. The grains are not packed very closely. The columnar structure of grains is not marked, but the alignment of columnar grains in the direction perpendicular to the incidence plane can be recognized.

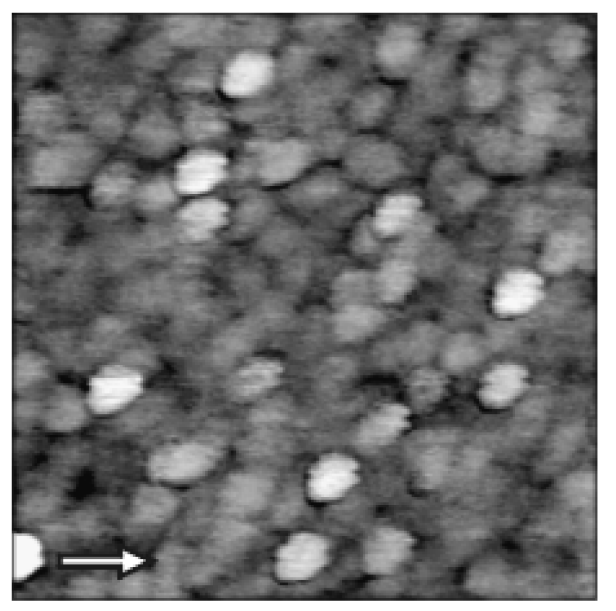

Fig. 1. $1 \mu \mathrm{m} \times 1 \mu \mathrm{m}$ AFM image of the morphological structure of a cobalt film $40 \mathrm{~nm}$ thick; the arrow indicates the projection of the vapor beam into the film plane.

It is worth noting that the origin of columnar grain structure can be explained by the geometric shadowing mechanism. The origin of the elongation of grains in the columns can be explained, similarly as the origin of the columns themselves, by taking into account only geometric causes.

$1 \mu \mathrm{m} \times 1 \mu \mathrm{m}$ AFM image of the surface of the cobalt film $100 \mathrm{~nm}$ thick is presented in Fig. 2. The morphological structure consists of grains elongated slightly in the direction perpendicular rather than parallel to the incidence plane. In comparison with the films $40 \mathrm{~nm}$ thick, the grains in the films $100 \mathrm{~nm}$ thick are somewhat larger and the film morphology is more continuous (the grains are closer to each other). Figure 2 shows that the observation of columnar grain structure in the films $100 \mathrm{~nm}$ thick becomes in fact more difficult. However, in this context, it should be noted that investigations carried out on the basis of magnetic and optical measurements, reported in the literature, prove that in evaporated films 


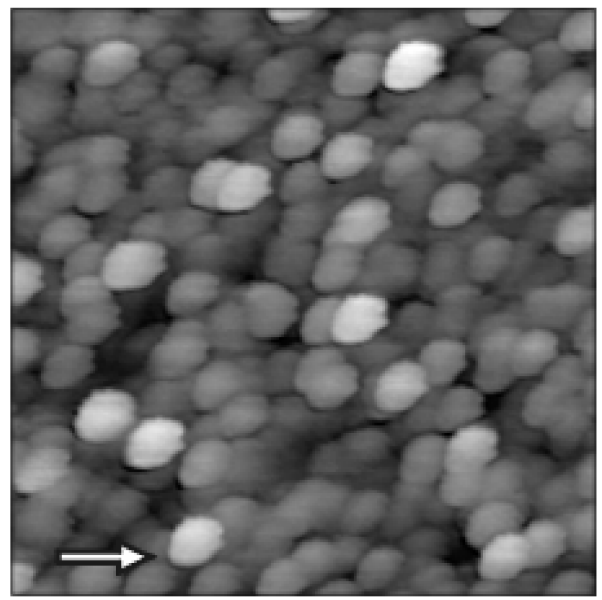

Fig. 2. $1 \mu \mathrm{m} \times 1 \mu \mathrm{m}$ AFM image of the morphological structure of a cobalt film $100 \mathrm{~nm}$ thick; the arrow indicates the projection of the vapor beam into the film plane.

the columnar grains generally align in the direction perpendicular to the incidence plane [2].

The images of the morphological structure obtained by AFM and TEM show that for the investigated films, deposited at an incidence angle of $45^{\circ}$, the degree of columnar grain alignment is generally low. This is in accordance with the results reported in Refs. [3-5], where well-defined columnar grain structures were observed for large deposition angles (larger than about $70^{\circ}$ ).

In the case of polycrystalline cobalt films, the contributions to the magnetic anisotropy originate from the geometric alignment of the grains through the shape anisotropy (the anisotropy of the demagnetizing field) as well as from the crystallographic alignment (texture) of the grains through the magnetocrystalline anisotropy $[2,6]$.

Electron diffraction measurements in the transmission electron microscope (TEM) were made to obtain information concerning the crystallographic orientation of the films. However, the recorded diffractograms show that the films $40 \mathrm{~nm}$ as well as $100 \mathrm{~nm}$ in thickness are polycrystalline with randomly oriented grains, i.e. no crystallographic texture could be detected by the method used.

\section{Conclusions}

In this paper, study of the morphological structure of cobalt films $40 \mathrm{~nm}$ and $100 \mathrm{~nm}$ in thickness, evaporated at an incidence angle of $45^{\circ}$ in a vacuum of about $10^{-5}$ mbar (simultaneously on unheated glass substrates and $\mathrm{NaCl}$ crystals), was carried out using AFM and TEM. Because of the fact that the investigated films were not deposited at large incidence angle, the shadowing effect was clearly pronounced neither for the films $40 \mathrm{~nm}$ thick nor for the films $100 \mathrm{~nm}$ thick. 
For the films $40 \mathrm{~nm}$ thick, the alignment of columnar grains in the direction perpendicular to the incidence plane was observed in images of the film surface recorded by AFM. This finding correlates well with the magnetic microstructure of these films, composed of in-plane magnetized domains running in the mentioned direction [1]. For the films $100 \mathrm{~nm}$ thick, the perpendicular alignment of columnar grains can also be found, although in fact with larger difficulty. For the films $40 \mathrm{~nm}$ and $100 \mathrm{~nm}$ thick, we could detect no crystallographic texture by electron diffraction in the TEM. To obtain information on the crystallographic alignment of grains, measurements by X-ray diffraction $(\Theta-2 \Theta$ spectra) [3] or by the X-ray Schulz method $[2,6]$ are necessary.

\section{Acknowledgments}

The work was supported by the Eódź University within Research Grant $505 / 692(2007)$

\section{References}

[1] W. Szmaja, J. Balcerski, Czech. J. Phys. 54, Suppl. D (20D245)04.

[2] K. Itoh, K. Okamoto, T. Hashimoto, J. Magn. Magn. Mater. 190, 176 (1998).

[3] A. Lisfi, J.C. Lodder, H. Wormeester, B. Poelsema, Phys. Rev. B 66, 174420 (2002).

[4] F. Liu, M.T. Umlor, L. Shen, J. Weston, W. Eads, J.A. Barnard, G.J. Mankey, J. Appl. Phys. 85, 5486 (1999).

[5] T. Otiti, J. Mater. Sci. 38, 1315 (2003).

[6] K. Hara, K. Itoh, M. Kamiya, K. Okamoto, T. Hashimoto, J. Magn. Magn. Mater. 161, 287 (1996). 